\title{
Study of construction accidents in Sri Lanka
}

\author{
Raufdeen Rameezdeen \\ Chaminda Pathirage \\ Saman Weerasooriya
}

\begin{abstract}
This paper summarizes the results of a study which examined the accidents that take place at Sri Lankan construction sites as recorded in the Industrial Safety Division (ISD) of the Ministry of Labour. The paper intends to provide a profile of construction accidents in Sri Lanka compared to other industries. In addition, it portrays the occupational and demographic characteristics of the victims. The number of fatal accidents are high in the construction industry compared to other industries. The ISD data show that falls are the single most common cause of fatalities. This is followed by electrocutions and "Struck-by" incidents. Falls are more frequently associated with roofs and scaffolding. "Struck-by" incidents are the major cause of non-fatalities. Electricians and Unskilled Workers have been found to be over-represented among accident victims. Workers over 60 years of age and under 20 years of age have been found to be over-represented among fatalities.
\end{abstract}

\section{Introduction}

By nature accidents are unplanned and uncontrolled events and in terms of operational probability is a class of events which incur at low level of expectancy, avoidability and intention (Laufer \& Ledbetter, 1997). Construction worker injuries have broad and adverse impacts, which include personal suffering of the injured worker, construction delays and productivity losses incurred by the construction contractor, higher insurance premiums that result from costly injuries and possible liability suits for all parties involved in the project. There are of course, many other impacts such as revenue losses on the part of the owner for late project delivery, reduced morale of work force and so on.

In any kind of health and safety management programme, the initial step could be to identify the hazards or disaster situations in the work environment. In this sense a detailed evaluation and a critical analysis of accidents in the construction industry is of immense importance. This paper summarizes the results of a study which examined the accidents that take place at Sri Lankan construction sites as recorded in the Industrial Safety Division (ISD) of the Ministry of Labour. The paper intends to provide a profile of construction accidents in Sri Lanka compared to other industries. In addition, it portrays the occupational and demographic characteristics of the victims. This information about past accidents might be useful to make predictions about the number and types of accidents that are likely to occur in the future. With this information, efforts may be expended to establish effective accident prevention programs. When the causes of serious accidents are understood, preventive procedures have a greater probability of being effective.

\section{Objectives and Research Methodology}

Study of construction accidents is a topic that has received considerable attention in developed countries. However, sufficient research work has not been done on this topic in Sri Lanka. Therefore, this study was carried out with the intention of critically analysing and evaluating the accidents that take place in the Sri Lankan construction sites. As such the objectives of this research effort were:

1. to identify the types of accidents recorded in the construction industry,

2. to find out the causes of accidents,

3. to examine the level of injury and fatalities in the construction industry, and

4. to determine the character and occupational category of workers who are prone to accidents.

The background to this research work was obtained through a comprehensive literature survey and a series of unstructured interviews with the following personnel:

1. The Deputy Commissioner of Labour, Ministry of Labour.

2. Chief Factory Inspecting Engineer of the Ministry of Labour.

3. Factory Inspecting Engineers based in Colombo South and Colombo North.

4. Director of Training and Development, Institute for Construction Training and Development.

5. The Deputy Director of Research, Institute for Construction Training and Development.

The study uses secondary data analysis methodology for the accident data recorded by the Industrial Safety Division of Ministry of Labour, Sri Lanka. ISD maintains records on occupational accidents that have resulted the victim to be absent from work for more than three days. 
These records include occupation of the injured worker, gender, age, time of accident, type of accident, position of injury, level of injury and the cause of accident. According to Section 61(1)(b) of Factories Ordinance No.45 of 1942 as amended, the employer should report every accident of the aforesaid magnitude to the relevant District Factory Inspecting Engineer within ten days after the victim resumes his employment (Chapter 144, 1980). Further, if the accident causes loss of life, the employer should inform it to the District Factory Inspecting Engineer immediately. The data from all district offices are compiled to a national database at the ISD. Following table illustrates the summary of accidents reported to ISD for year 2001.

\begin{tabular}{|l|c|c|c|}
\hline & Fatal & Non-fatal & Total \\
\hline Construction & 10 & 87 & 97 \\
\hline $\begin{array}{l}\text { All other industries } \\
\text { combined }\end{array}$ & 31 & 2150 & 2181 \\
\hline Total & 41 & 2237 & 2278 \\
\hline
\end{tabular}

In order to obtain a detailed evaluation of certain results of the analysis, an interview survey was conducted among a selected group of Project Managers who had experience of over 10 years managing construction sites in Sri Lanka. In total 9 Project Managers were interviewed using a semi-structured interview guideline.

\section{Construction Accidents}

The term 'Accident' has been defined by Laney (1982) as "an uncontrollable occurrence which results injuries or damages". Another definition that has gained popularity is "an unplanned not necessarily injurious or damaging event that interrupts or disrupts the completion of an activity" (Laufer \& Ledbetter, 1997). The safety record of the construction industry is considered to be very poor compared to other industries (Hinze \& Appelgate, 1991). Davis and Tomasin (1990) have revealed three important reasons for this poor safety performance in the construction industry, which in turn has given rise to high rate of accidents. They are:

1. short term and transitory nature of the industry.

2. lack of controlled working environment, and

3. complexity and the diversity of size of organisation within the industry.

The Section $6(1)(A)$ to $6(1)(D)$ of Workmen's Compensation Ordinance No.19 of 1934 as amended, has divided accidents into four categories as follows (Chapter 158, 1980):

\section{Death}

2. Permanent total disablement - The Permanent total disablement means such disablement, whether of a temporary or permanent nature, as incapacitating a workman for all work which he was capable of performing at the time of the accident.
3. Permanent partial disablement - Permanent partial disablement means the disablement of a permanent nature and such disablement reduces the earning capacity of the disabled from employment which he was capable of undertaking at the time of the injury. 4. Temporary disablement - Temporary disablement means where the disablement is of temporary nature, such disablement reduces the earning capacity of a workman in the employment in which he was engaged at the time of accident.

Even though accidents could be classified in several ways, the categorisation of Laufer \& Ledbetter (1997) based on the level of injury or damage is the most popular. They categorized accidents into four types as follows:

1. Lost day cases - Cases which bring absence from their work.

2. Doctor's cases - None lost workday cases that are attended by doctors.

3. First aid cases - None lost day cases requiring first aid treatment.

4. None injury cases - 'Accident' not resulting in personal injury but including property damage or productivity disruption.

In this research only lost day cases are considered due to the fact that ISD data cover causes which come under the Factory Ordinance No. 45 of 1942 (Chapter $144,1980)$. Data related to other three categories are not available.

The main drawback of this study is that it is based on data from safety inspection authorities. Though the occupational safety legislation in Sri Lanka requires the employer to report every accident of a certain magnitude to the relevant District Factory Inspecting Engineer within ten days after the victim resumes his employment, it is, however, possible that employers did not report all serious accidents to authorities due to various reasons. This can be noted as one of the limitations of this study. There is no other source of information on construction accidents in Sri Lanka.

\section{Profile of Construction Accidents in Sri Lanka}

\subsection{Severity}

Accidents can be broadly divided into two, as fatal and non-fatal based on the severity. Hinze \& Bren , (1995) cited fatal accidents as "One in which at least one person is killed (but excluding confirmed suicides) within 30 days of the occurrence of the accident". Therefore all other accidents that do not fall into the category of fatal accidents are considered to be nonfatal accidents. Research has shown that the severity of an accident has an inverse relationship to frequency (Laufer \& Ledbetter, 1997). 
The number of fatal accidents in the Sri Lankan construction industry is significantly high compared to other industries. According to Figure 1, 53\% of fatal accidents have occurred in the construction industry. This figure is relatively low for non-fatal accidents $(6 \%)$. Construction industry is the largest contributor to fatal accidents, followed by Mining and Quarrying. These observations show that severity of construction accidents are higher compared to other industries. This proves poor safety performance in the industry and how vulnerable the workers are in construction sites. Accidents at construction sites are more often serious than accidents in factories; the severity of a fatal accident is as much as nine times higher in the construction industry than in other industries.

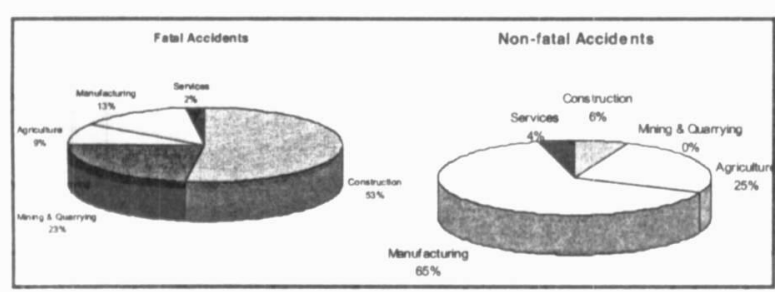

Figure 1: Severity of construction accidents compared to other industries (per Rupee one billion output between 1984-2001)

Figure 2 provides the trend of fatal accidents during the past two decades. It shows that construction has always had a higher fatality rate except for a brief period in early 1990's. Peak of fatal accidents in construction occur in 1987, which then drop drastically to the lowest value of the two decades. Another smaller peak could be observed in 1994 again with a sudden drop afterwards. In contrast, the number of fatal accidents in other industries gradually reduces with time.

Figure 3 shows the trend of non-fatal accidents during the same period. Despite the two peaks in 1989 and 1992 respectively, the general trend of construction accidents is similar to other industries. Non-fatal accidents in construction and in other industries reduce over time.

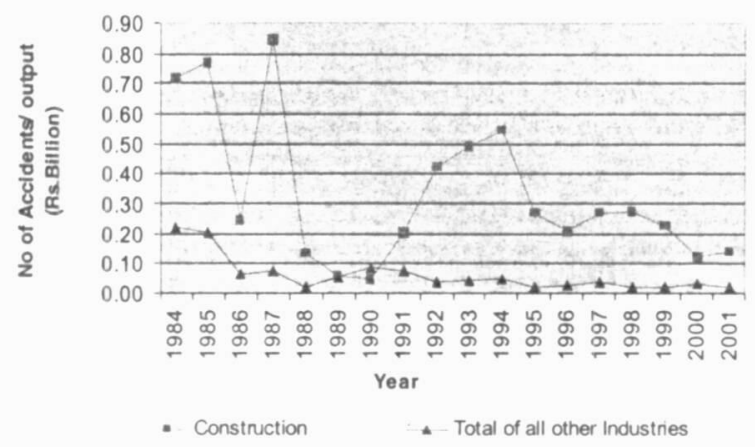

Figure 2: Trend of fatal accidents ( per Rupee one billion output)

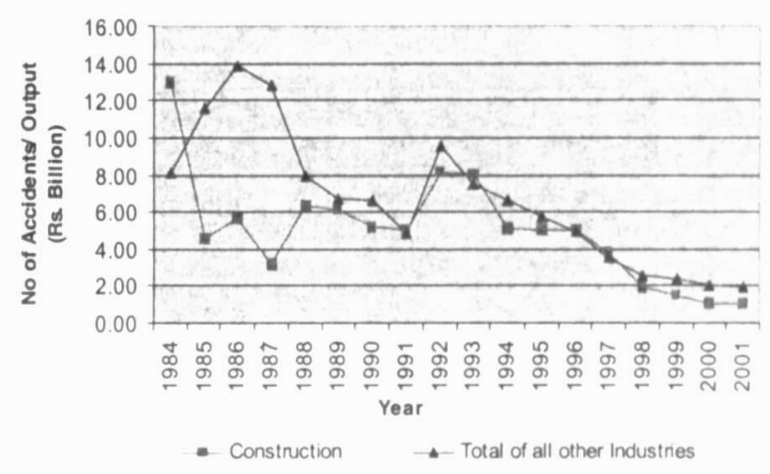

Figure 3: Trend of non-fatal accidents (per Rupee one billion output)

\subsection{Causes of Construction Accidents}

Davis and Tomasin (1990) have identified the followings as causes of accidents:

\section{Fall}

2. Struck-by or struck-against objects

3. Lifting and carrying; over-extension

4. Machinery

5. Electricity

6. Transport

7. Fire and explosion

According to this categorisation 'fall' includes people falling from one level to another, falling of plant and material including collapse of a structure or part of it. Langford et al. (2000) identified the factors behind construction accidents as psychological and environmental. The environment factors are:

1. site conditions

2. site tidiness

3. availability of technology and resources

4. inter and intra group co-operation

5. control and supervision of work

6. effectiveness of long term planning

7. role and position of the safety officers and safety representatives

8. payment structure.

Whereas, the psychological factors consist of

1. care and attention by the individuals

2. skill and experience brought to the job

3. safety training

4. accuracy of subjective risks evaluation

5. origins of safety norms

6. perceived responsibility

7. feeling of competent autonomy of fatalism

Accordingly an accident can be considered as a chain of events. The starting point of the chain is the prevalence of a conducive environment that can trigger off an accident at any moment. Unsafe act is the next event which causes an accident to take place. Once the accident has taken place it follows with an injury except when it can be categorized as a none injury case. 


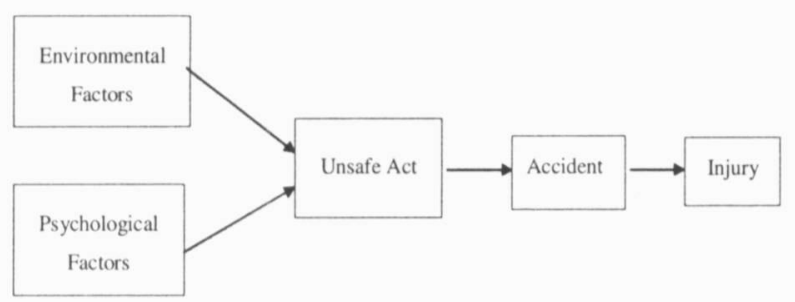

The magnitude of the injury may vary according to the classification of accidents given earlier.

When accidents are recorded in the ISD, they are coded into one of seven event types: (1) Falls; (2) Struck By; (3) Struck Against; (4) Caught in Between; (5) Electrocution; (6) Exposure to harmful substances; and (7) Other. The percentage of construction accidents in each of these event types is shown in Figure 4. Falls have been the most general accident type in the construction industry for fatalities. Struck-by incidents are the most important causal factor for non-fatal accidents. An interesting observation is that about $6 \%$ of fatal and $1 \%$ of non-fatal accidents are caused by exposure to harmful substances. Even though falls and struck-by incidence can be considered as common causes of construction accidents due to the nature of the industry, electrocution and exposure to harmful substances cannot be overlooked.

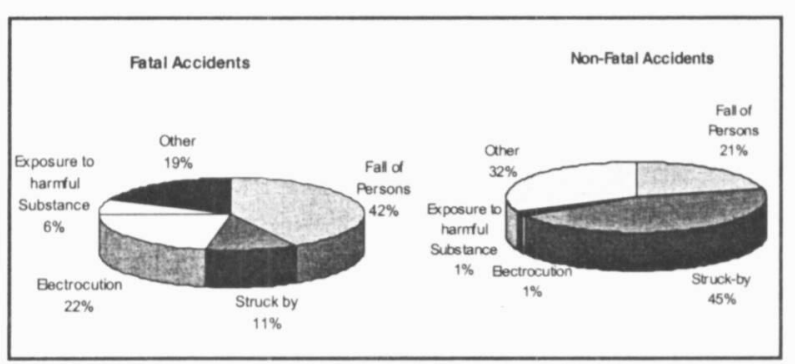

Figure 4: Causes of construction accidents in Sri Lanka

\subsection{Position of injury}

When reporting an accident, the position of the injury should be specified according to the ISD categorization. If it is more than one position, "multiple injuries" category accommodates that data. If an accident affects the overall health rather than a part of the body, the reporter could select the "injury to overall health". Figure 5 provides the results of the analysis for fatal and nonfatal accidents separately. The head, neck and multiple injuries are commonly recorded in fatal construction accidents. The hand, leg and foot were hurt most often in non-fatal accidents. The most typical injuries due to non-fatal accidents were sprains and strains, cuts and lacerations, open wounds and fractures. As can be expected, multiple injuries are comparatively high for fatal accidents.

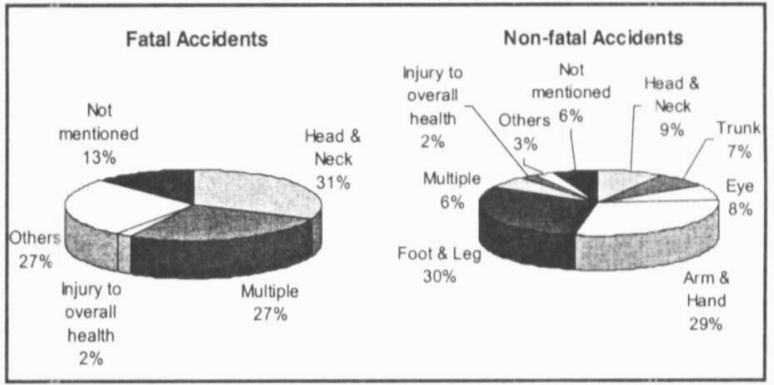

Figure 5: Construction accidents according to the position of injury

\subsection{Timing of accident}

ISD data on time of the incident was extracted and analyzed to get an understanding on the distribution of accidents over a day. A relatively high percentage of fatal accidents have occurred during 2:00 p.m. - 6:00 p.m. It may be due to loss of productivity after lunch. Drop of alertness and reflexes after lunch may be the cause of high accident rate during this time period. Figure 6 provides the results of the analysis.

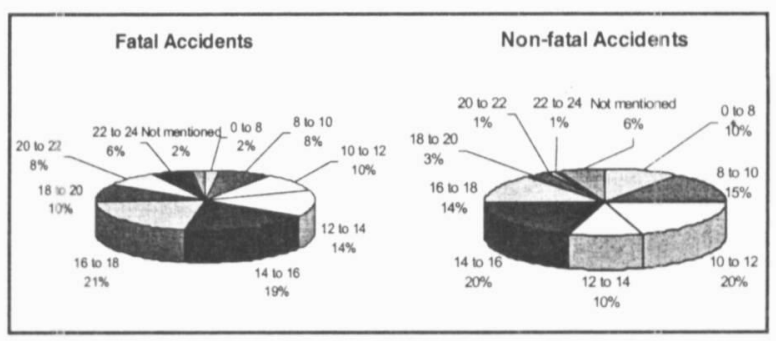

Figure 6: Construction accidents according to the time of the incident

\section{Occupational and Demographic Characteristics of the Victims}

\subsection{Occupation}

The results concerning the victims' occupation are given in Figure 7. Percentages given in paranthesis indicate the representation of the particular occupation in the national construction workforce (Jayawardane \& Gunewardene, 1998). Electricians and Unskilled Workers are found to be overrepresented among accident victims. The proportion of fatal victims in the electrician trade $(7 \%)$ was higher than their representation in the construction workforce $(1.9 \%)$. Similarly, the proportion of unskilled victims on non-fatal accidents $(71 \%)$ was higher than their representation in the construction workforce $(50.4 \%)$. On the contrary, Masons and Carpenters are very much under-represented among accident victims. 


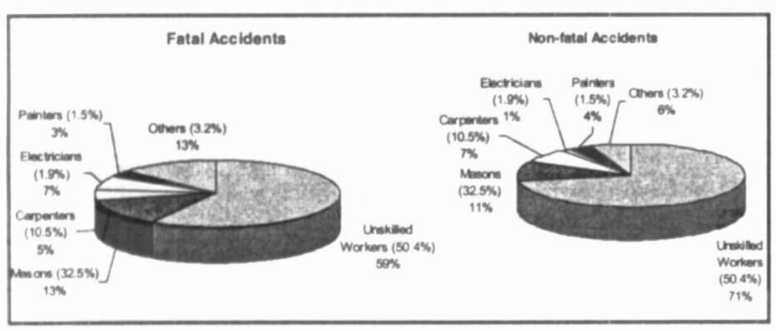

( )gives the representation of each trade in the national construction workforce

Figure 7: Occupational categorization of accident victims

\subsection{Age group}

The results concerning the victims' ages are given in Figure 8 . Workers over 60 years of age and under 20 years of age are found to be over-represented among fatalities. In addition, the accident risk has been found to increase with age. The proportion of victims under 20 years of age $(10 \%)$ was higher than their representation in the construction workforce $(2.7 \%)$. Similarly, the proportion of victims over 60 years of age $(7 \%)$ was higher than their representation (2.4\%). However, workers over 60 years of age are not found to be common victims in non-fatal accidents.

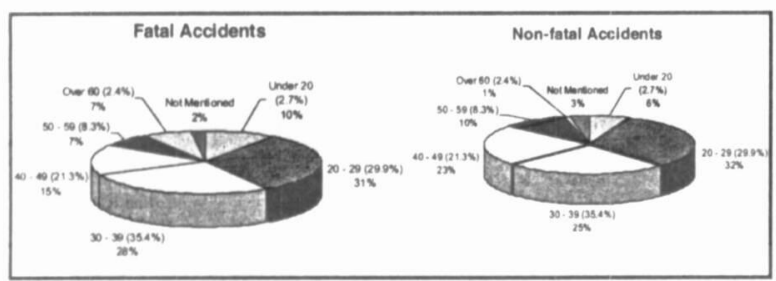

( ) gives the cohort representation in the national construction workforce

Figure 8: Categorization of accident victims according to age

\section{Discussion}

The construction industry constitutes a problem area for occupational safety. The number of fatal accidents in construction industry is high compared to other industries. Although fatal accidents in all other industries show a decreasing trend, construction industry shows otherwise in certain periods. There are many possible explanations for the high accident rates in the construction industry, particularly the changing site conditions that require risk-taking. The study also revealed that for every 13 non-fatal accidents one fatal accident occurs in construction. Table 1 compares this ratio with other industries.
Table 1: Fatalities in construction compared to other industries

\begin{tabular}{|l|c|}
\hline & Ratio of fatal : non-fatal accidents \\
\hline Construction & $1: 13$ \\
\hline $\begin{array}{l}\text { All other industries } \\
\text { combined }\end{array}$ & $1: 115$ \\
\hline
\end{tabular}

Falls were clearly the dominant cause among the fatalities. The specific causes of the falls were evaluated using interviews with a selected group of Project Managers. Based on the experience of these Project Managers, the most common causes are listed in the order of occurrence as follows:
1. Off roof
2. Off scaffolding
3. Off ladder
4. Collapse of scaffolding
5. Off structure
6. Through floor opening
7. Collapse of structure

A significant number of fatalities appear to be related to work performed on roofs and on scaffolding. "Electrocution" and "exposure to harmful substances" are considered to be significant causes for fatal accidents following falls. An examination of the electrocutions shows the causes of these fatalities in order of priority as follows:
1. Direct contact with live wire
2. Ladder contact with power line
3. Crane boom with power line
4. Materials hit power line

A serious concern expressed by most of the Project Managers was the high percentage of victims exposed to harmful substances while at work. There aren't any stringent legal requirements in Sri Lanka dealing with handling of hazardous materials in construction work. Such legal underpinning will certainly help in curbing accidents of this nature. "Electrocution" and "exposure to harmful substances" are related more to the work practice, training and use of safety gear than to the psychological condition of the victim at the time of accident.

"Struck-by" incidents are the major cause of nonfatalities. An examination of "Struck-by" incidents using the interview results show the causes of these accidents ranked as follows:

1. Falling of object

2. Run over by heavy equipment

3. Crane, boom or load. 
While a wealth of ISD raw data exists, it is not rigorously analyzed on a regular basis by Safety Authorities. Careful and regular analysis of data could yield very meaningful information to employers in those areas over which greater attention should be devoted. With such information at their disposal, contractors could be able to provide greater focus over certain areas when preparing their safety plans. Safety programs could be modified directly focusing on those areas identified as warranting greater attention. Work sequences and approaches to perform certain work could be altered so as to reduce risks. Falls are the major cause of fatalities. Safety efforts must be focussed on fall protection if dramatic improvements in safety performances are to be made.

\section{Conclusions}

The number of fatal accidents in construction industry is high compared to other industries. Although fatal accidents in all other industries have a decreasing trend, construction industry shows otherwise in certain periods. The study revealed that for every 13 non-fatal accidents one fatal accident occurs in construction. The ISD data show that falls are the single most common cause of fatalities. This is followed by electrocutions and "Struck-by" incidents. Falls were more frequently associated with roofs and scaffolding. "Struck-by" incidents are the major cause of non-fatalities. The head and neck were injured most often in fatal construction accidents. The hand, leg and foot were hurt most often in non-fatal accidents. A relatively high percentage of accidents have occurred during 2:00 p.m. - 6:00 p.m. Electricians and Unskilled Workers are over-represented among accident victims. Workers over 60 years of age and under 20 years of age are over-represented among fatalities. In addition, the accident risk is found to increase with age.

As falls being the major cause of fatalities, safety efforts must be focussed on fall protection if dramatic improvements in safety performances are to be made. A serious concern expressed by most of the Project Managers was the high percentage of victims exposed to harmful substances while at work. There aren't any stringent legal requirements in Sri Lanka dealing with handling of hazardous materials in construction work. Such legal underpinning will certainly help in curbing accidents of this nature.

\section{References}

Chapter 144., (1980), Legislative Enactment of Democratic Socialist Republic of Sri Lanka, Vol 7.

Chapter 158., (1980), Legislative Enactment of Democratic Socialist Republic of Sri Lanka, Vol 7.

Davis, V. J., and Tomasin, K., (1990), Construction Safety Handbook, Thomas Telford, London.

Hinze, J., Appelgate. L.L., (1991), Cost of Construction Injuries, The Journal of Construction Engineering and Management, 117(3), pp 537-550.

Hinze, J., and Bren. D., (1995), Analysis of fatalities and injuries due to power line contacts, The Journal of Construction Engineering and Management, 122 (2), pp177-182.

Jayawardane,.A.K.W. and Gunewardene (1998), Construction Workers in Developing Countries; a Case Study of Sri Lanka., The Journal of Construction Management and Economics, 16 (6) pp 521-530.

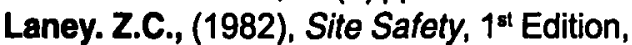
Longman, Inc, New York.

Langford. D., Rowlinson. S., and Sawacha, E., (2000), Safety Behaviour and Safety Management: its influence on the attitudes of workers to the UK construction industry. The Journal of Engineering Construction and Architectural Management, 7(2), pp 133-140.

Laufer. A., Ledbetter. W.B., (1997), Assessment of Safety Performance Measures at Construction Sites, The Journal of Construction Engineering, 112(4),pp 530-541. 